\title{
Differential mRNA expression of the related extracellular matrix glycoproteins SC1 and SPARC in the rat embryonic nervous system and skeletal structure
}

\author{
Andrea J. Mothe, Ian R. Brown* \\ Department of Zoology, University of Toronto at Scarborough, Toronto, Ontario, Canada, M1C 1A4
}

Accepted 17 October 2000

\begin{abstract}
SPARC is a multifunctional extracellular matrix glycoprotein that shares partial sequence homology with SC1. These extracellular matrix molecules are thought to play important roles in modulating cellular interactions. In vitro, SPARC has been shown to exhibit anti-adhesive activity. In the present investigation, in situ hybridization is used to compare the expression patterns of SC1 and SPARC mRNA in the rat embryo. Results show that SC1 and SPARC expression is spatially and temporally regulated. SC1 mRNA is strongly expressed in the embryonic brain and spinal cord, whereas SPARC mRNA is enriched in craniofacial cartilage and skeletal structures. This differential expression pattern in the rat embryo suggests that SC1 plays an important role in the developing nervous system, whereas SPARC participates primarily in events associated with skeletal development. However at embryonic day 17, SC1 and SPARC mRNA show parallel expression patterns in areas of the cerebellum undergoing cell migratory events. (C) 2001 Elsevier Science B.V. All rights reserved.
\end{abstract}

Theme: Cellular and molecular biology

Topic: Gene structure and function

Keywords: Anti-adhesive; ECM; In situ hybridization; Spinal cord; Neural development

\section{Introduction}

It is well established that the extracellular matrix (ECM) plays an integral role during developmental events. An ECM is present within mammalian embryos from the two-cell stage and is a component of the environment of most cell types, although the composition and the regulation of ECM molecules differs between tissues [1]. SPARC (secreted protein, acidic, and rich in cysteine) is a well characterized component of the ECM. SPARC/osteonectin was originally isolated from developing bone and thought to be bone-specific [36], but later was shown to be expressed by a wide variety of mineralized and nonmineralized tissues. SPARC is a multifunctional protein that regulates cell shape and adhesion, cell cycle pro7642 .

*Corresponding author. Tel.: +1-416-287-7413; fax: +1-416-287-

E-mail address: ibrown@scar.utoronto.ca (I.R. Brown). gression, and cell-matrix interactions, and thus has been associated with development, remodeling, cell turnover, and tissue repair [41]. SPARC expression is thought to modulate interactions between cells and the ECM by inhibiting cell spreading and by regulating the production of other ECM molecules [23].

Previously, we have described the cloning of SC1 which encodes a secreted ECM glycoprotein that shows partial sequence similarity at its carboxyl-terminus to SPARC [15]. SC1 and SPARC share homologous domains which bind calcium, certain metals and cytokines, and other ECM molecules. SPARC has been shown to possess anti-adhesive properties since it inhibits cell spreading, disassembles focal adhesions, and induces rounding of cultured endothelial cells and fibroblasts [29]. Similarly, the human homologue of SC1 (hevin) inhibits attachment and spreading of endothelial cells on fibronectin substrates, and hevin-treated cells also induce a rounded morphology which do not form focal adhesions [11]. The anti-adhesive 
properties of SC1 and SPARC lead to cell rounding and changes in cell shape that ultimately result in the disruption of cell-matrix interactions. SPARC has been described as a matricellular multidomain protein that plays an important role in modulating cell-matrix interactions, rather than more conventional structural functions assigned to traditional ECM proteins [5]. SPARC, SC1/hevin, thrombospondins 1 and 2 , tenascins $\mathrm{C}$ and $\mathrm{X}$, and osteopontin have been classified as secreted matricellular glycoproteins that appear to perform related functions such as exhibiting anti-adhesive effects [5].

Previous studies in our laboratory have examined SC1 and SPARC expression in the central nervous system during postnatal development and in the adult [15,2022,24]. SC1 and SPARC are both expressed by glial cells during postnatal development of the brain. For example, in the cerebellum, SC1 and SPARC are expressed in Bergmann glial cells and their radial fibers which project into the synaptic-rich molecular layer [20,21]. Recently, we have shown that SC1 mRNA is transported into the processes of Bergmann glia at specific stages of development and in the mature cerebellum, allowing for the possibility of a local control of SC1 protein synthesis [24].

In the present study we have used in situ hybridization to compare the expression pattern of SC1 and SPARC mRNA and determine whether these transcripts show unique or overlapping patterns of expression in the rat embryo. We found that SC1 mRNA was strongly expressed in the developing brain and spinal cord from embryonic day 13 to 17, whereas SPARC mRNA was enriched in craniofacial cartilage, ribs, vertebrae, and skeletal structures. However, SC1 and SPARC mRNA are also expressed in regions of cell proliferation and areas of cell migration in the E17 hindbrain. Therefore, SC1 and SPARC may exhibit some overlap of function given their partial sequence homology. However, their differential expression pattern in the embryonic rat suggests that SC1 plays an important role in the developing central nervous system, whereas SPARC participates in events associated with skeletal development.

\section{Materials and methods}

\subsection{Riboprobe synthesis}

SC1 and SPARC riboprobes were generated by in vitro transcription with a RNA transcription kit from Promega. A 295 bp EcoR1-HindIII fragment of the rat SC1 cDNA [15] was used to generate ${ }^{32} \mathrm{P}$ or ${ }^{35} \mathrm{~S}$-labelled riboprobes, for use in Northern analysis and in situ hybridization, respectively. Linearization with EcoR1 or HindIII and subsequent in vitro transcription incorporating ${ }^{32} \mathrm{P}$ or ${ }^{35} \mathrm{~S}$ labelled UTP with SP6 or T7 RNA polymerases produced antisense and sense SC1 riboprobes, respectively. SPARC riboprobes were generated from a $450 \mathrm{bp}$ fragment of mouse SPARC cDNA [12]. Antisense probe was generated by linearization with XbaI and transcription with SP6, and the control sense probe was obtained by linearization with PstI and transcription with T7 RNA polymerase.

\subsection{Northern blot analysis}

Total RNA was isolated from brain (cerebral hemispheres) and kidney from adult Wistar rats. Aliquots of 5 $\mu \mathrm{g}$ were separated on $1.5 \%$ agarose gels containing $6 \%$ formaldehyde and blotted onto Biotrans nylon membrane. Blots were prehybridized at $60^{\circ} \mathrm{C}$ for $3 \mathrm{~h}$ in buffer containing $50 \%$ formamide, $5 \times \mathrm{SSC}, 5 \times$ Denhardt's solution $(0.1 \%$ Ficoll, $0.1 \%$ polyvinylpyrolidone, $0.1 \%$ bovine serum albumin), $50 \mathrm{mM}$ sodium phosphate ( $\mathrm{pH} 6.5$ ), $0.1 \%$ SDS, $1 \%$ glycine, $250 \mu \mathrm{g} / \mathrm{ml}$ yeast tRNA, and $250 \mu \mathrm{g} / \mathrm{ml}$ sheared herring testes DNA. Hybridization was carried out overnight in the same buffer containing ${ }^{32}$ P-labelled antisense SC1 or SPARC riboprobes. Blots were washed under low stringency conditions in $1 \times \mathrm{SSC}, 0.1 \% \mathrm{SDS}$ at $42^{\circ} \mathrm{C}$, and under high stringency conditions at $70^{\circ} \mathrm{C}$ in $0.1 \times \mathrm{SSC}, 0.1 \% \mathrm{SDS}$, and exposed to Kodak X-OMAT film at $-70^{\circ} \mathrm{C}$ with a Cronex Lightening Plus intensifying screen. Duplicate blots were stained with methylene blue to verify equal loading of RNA in each lane.

\subsection{Tissue preparation and pretreatments}

Embryos were removed from timed-pregnant anesthetized Wistar rats at embryonic day 13 (E13), E15, and E17. Rat embryos were removed from their extraembryonic membrane and fixed in PBS-buffered $4 \%$ paraformaldehyde overnight at $4^{\circ} \mathrm{C}$, and then equilibrated by subsequent overnight incubations in 5\%, 10\%, and $20 \%$ sucrose in PBS, pH 7.4. Embryos were mounted in OCT embedding compound and stored at $-70^{\circ} \mathrm{C}$ until use. Serial cryostat sections of $20 \mu \mathrm{m}$ were collected onto gelatin-coated slides ( $1 \%$ gelatin, $0.5 \%$ chromium potassium sulfate) and air-dried overnight. Sections were postfixed in $4 \%$ paraformaldehyde for $30 \mathrm{~min}$ and rinsed in 0.1 $\mathrm{M}$ PBS. Sections were incubated with $0.5 \mu \mathrm{g} / \mathrm{ml}$ of protease $\mathrm{K}$ at $37^{\circ} \mathrm{C}$ for $20 \mathrm{~min}$ in $100 \mathrm{mM}$ Tris, $50 \mathrm{mM}$ EDTA (pH 7.5), followed by a $10 \mathrm{~min}$ wash in $0.1 \mathrm{M}$ triethanolamine (TEA), $\mathrm{pH}$ 8.0, and dehydration through an ethanol series containing $0.33 \mathrm{M}$ ammonium acetate.

\subsection{In situ hybridization}

Tissue sections were prehybridized for $1 \mathrm{~h}$ at $42^{\circ} \mathrm{C}$ in a solution containing $50 \%$ formamide, $750 \mathrm{mM} \mathrm{NaCl}, 5 \times$ Denhardt's ( $0.1 \%$ Ficoll, $0.1 \%$ polyvinylpyrolidone, $0.1 \%$ bovine serum albumin), $0.1 \%$ SDS, $100 \mathrm{mM}$ dithiothreitol, and $50 \mathrm{mM}$ PIPES ( $\mathrm{pH}$ 7.6). Hybridization was carried out in the same solution containing $1.5 \times 10^{6} \mathrm{cpm}$ per section of ${ }^{35} \mathrm{~S}$-labelled antisense or sense riboprobes at $55^{\circ} \mathrm{C}$ for 14-18 h. After hybridization, slides were rinsed in TES 
buffer $(10 \mathrm{mM}$ Tris, $1 \mathrm{mM}$ EDTA, $500 \mathrm{mM} \mathrm{NaCl}, \mathrm{pH}$ 8.0 ), followed by a $20 \mathrm{~min}$ incubation at $37^{\circ} \mathrm{C}$ in TES buffer containing $20 \mu \mathrm{g} / \mathrm{ml}$ RNase A. Slides were then washed in TES buffer containing $300 \mu \mathrm{M} \beta$-mercaptoethanol ( $\beta$-ME) at $37^{\circ} \mathrm{C}$ for $1 \mathrm{~h}$ followed by a $1 \mathrm{~h}$ wash at $70^{\circ} \mathrm{C}$ in $0.1 \times \mathrm{SSC}$ and $300 \mu \mathrm{M} \beta$-ME. After posthybridization washes, sections were dehydrated through an ethanol series containing $0.33 \mathrm{M}$ ammonium acetate and air dried. Slides were processed for autoradiography with Kodak NTB2 liquid emulsion, and exposed for 4-6 weeks at $4^{\circ} \mathrm{C}$. Slides were developed in Kodak Dektol developer for $2.5 \mathrm{~min}$, fixed for $5 \mathrm{~min}$ in Kodak Rapid Fix, washed in running water for $15 \mathrm{~min}$, and air dried overnight. Emulsion-coated sections were counterstained with cresyl violet and coverslipped with 50:50 xylene/permount.

Sections were photographed with a Leica M402 Makroscope to obtain low magnification photos which were scanned with a Bio-Rad scanner using Multi-Analyst software v.1.1. High magnification images were obtained with a Zeiss Axiophot microscope and Northern Eclipse 5.0 imaging software. Data representative of at least five animals of each embryonic age from three different litters are shown.

\section{Results}

\subsection{Northern blot analysis of SC1 and SPARC $m R N A$ expression}

Northern blot analysis (Fig. 1) of RNA isolated from rat brain (B) and kidney (K) indicated that the $\mathrm{SC} 1$ riboprobe recognized a 2.7 kilobase $(\mathrm{kb})$ mRNA species whereas the SPARC riboprobe identified a $2.2 \mathrm{~kb}$ message. As shown in Fig. 1, the SC1 and SPARC riboprobes, which were subsequently used in the in situ hybridization study, did not cross-hybridize. SC1 and SPARC mRNA were strongly expressed in brain tissue, whereas lower levels of SPARC mRNA were apparent in kidney. SC1 mRNA was not detected in kidney.

\subsection{Contrasting patterns of SC1 and SPARC mRNA expression in the embryonic rat}

Sagittal sections of embryos were processed for in situ hybridization to investigate mRNA expression patterns and counterstained with cresyl violet to show parallel tissue morphology (Fig. 2A). At embryonic day 13 (E13), SC1 mRNA was expressed at high levels in the central nervous system in the spinal cord (SP) and brain (CNS) (Fig. 2B). In contrast, mRNA encoding the related extracellular matrix glycoprotein SPARC was enriched in the developing vertebrae ( $\mathrm{V}$ in Fig. 2D) which ensheath the spinal cord. Both transcripts were expressed in the liver (L) and heart $(\mathrm{H})$ (Fig. 2B and D). The SC1 and SPARC riboprobes used in this study were specific and did not show
SC1

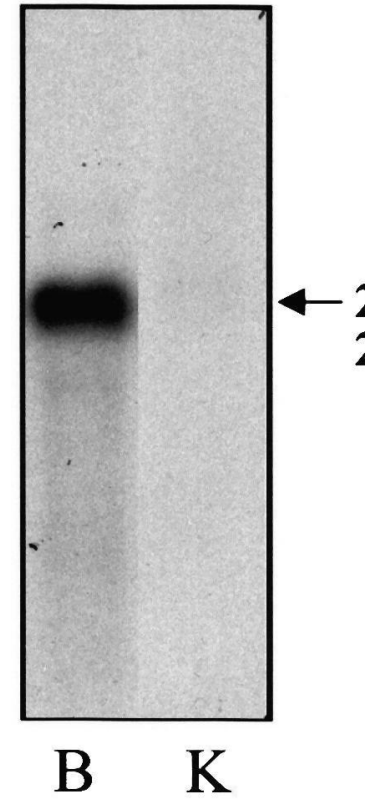

SPARC

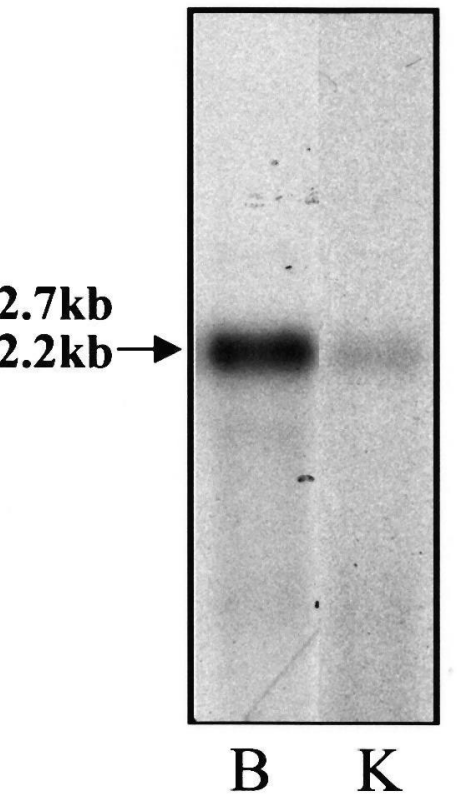

Fig. 1. Northern blot analysis of SC1 and SPARC mRNA expression. The SC1 and SPARC riboprobes utilized in this study do not show crosshybridization. The SC1 riboprobe recognizes a 2.7 kilobase $(\mathrm{kb})$ mRNA species, whereas the SPARC riboprobe detects an mRNA species of 2.2 $\mathrm{kb}$. Both SC1 and SPARC mRNA are abundantly expressed in the brain (B). Lower levels of SPARC are found in kidney (K), whereas SC1 mRNA is undetectable in kidney. B, brain; K, kidney.

cross-hybridization, as demonstrated previously by Northern blot analysis [15], and as shown in Fig. 1. Adjacent sections hybridized with sense riboprobes indicated background levels of hybridization as shown in Fig. 2C. Some sections were pretreated with RNase enzyme prior to hybridization with the antisense probe as an additional control (data not shown). The RNase treatment resulted in elimination of the hybridization signal.

Fig. 3, at higher magnification, highlights the differential expression patterns of $\mathrm{SC} 1$ and SPARC mRNA. SC1 mRNA was expressed in the spinal cord (SP) but not in adjacent vertebrae (V) (Fig. 3A), while the reverse pattern was observed for SPARC mRNA (Fig. 3B). Both mRNAs were expressed in the pia mater (PM), a cellular layer which covers the brain and spinal cord (Figs. 3A and B). A pronounced SC1 mRNA signal was noted in the nasal process (NP in Fig. 3D) in addition to an intense signal in the epithelium of the mandibular component of the first branchial arch (MA in Fig. 3D).

\subsection{SC1 mRNA is localized to neural regions whereas SPARC MRNA is enriched in the developing skeletal system}

The differential pattern of expression between SC1 and SPARC mRNA was emphasized in Fig. 4 in the develop- 
A

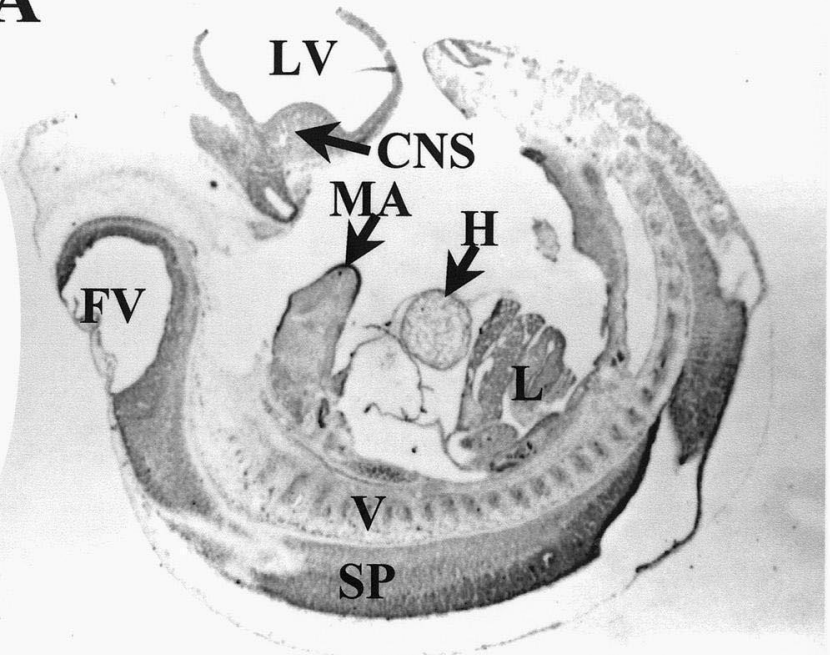

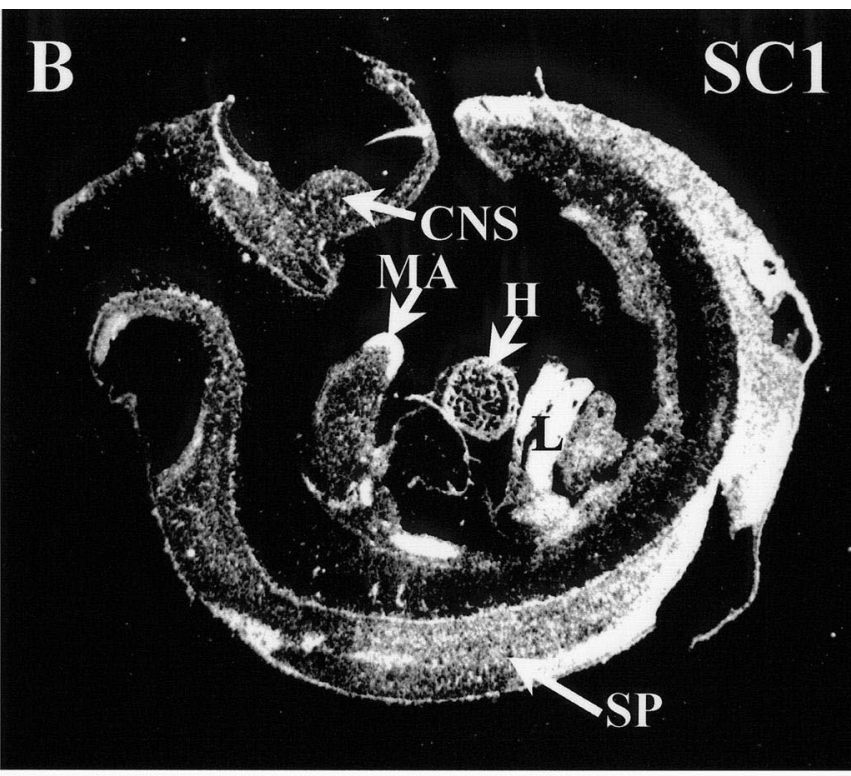

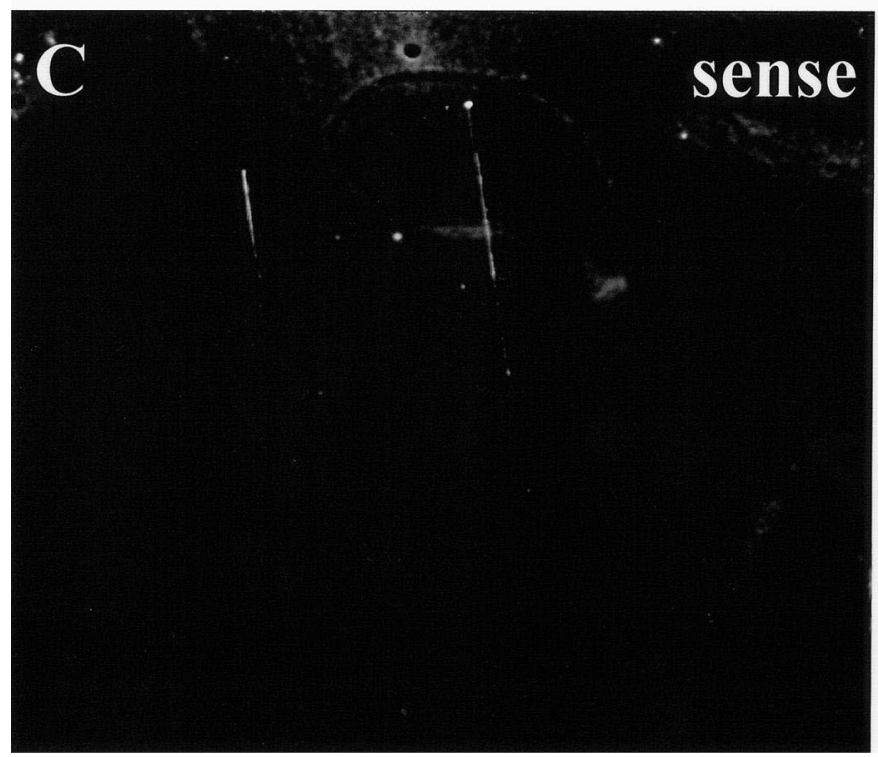

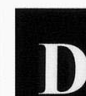

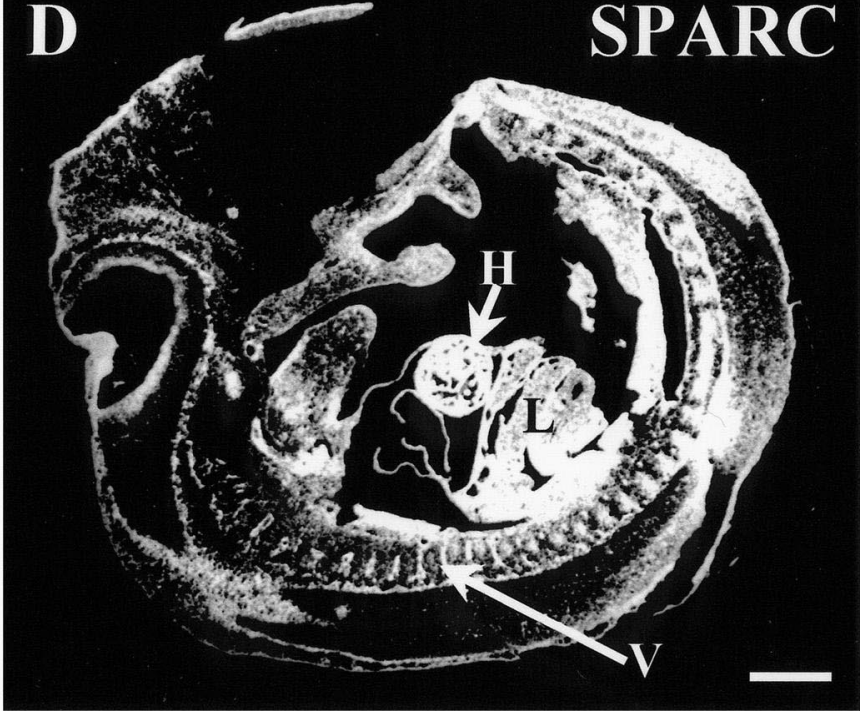

Fig. 2. In situ hybridization of SC1 and SPARC mRNA in the E13 rat embryo. Panel A is an embryonic day 13 (E13) sagittal section stained with cresyl violet to indicate tissue morphology as seen by brightfield microscopy. The other panels show silver grains indicating SC1 and SPARC mRNA distribution by darkfield microscopy following radioactive in situ hybridization. As shown in panel B, SC1 mRNA is expressed at high levels in the central nervous system tissue of the developing spinal cord (SP), and brain (CNS) of the E13 rat. A localized signal is also apparent in the mandibular component of the first branchial arch (MA). In contrast, SPARC expression is enriched in the developing vertebrae (V), a region that does not show abundant SC1 mRNA expression (panel D). Both transcripts are expressed in heart (H) and liver (L). Panel C shows an adjacent section hybridized with SPARC sense riboprobe indicating background levels of hybridization. Similar results were obtained with the SC1 antisense riboprobe (data not shown). Scale bar $=700 \mu \mathrm{m}$. CNS, central nervous system; FV, fourth ventricle; H, heart; L, liver; LV, left ventricle; MA, mandibular arch; SP, spinal cord; V, vertebrae.

ing central nervous system and craniofacial cartilage at E15. A strong hybridization signal for SPARC mRNA was apparent in cartilagenous zones of the cranium, as indicated by arrows (Fig. 4C). In contrast, SC1 mRNA was not expressed in these zones, and appeared more intense in the developing central nervous system (CNS in Fig. 4B). Both SC1 and SPARC mRNA were expressed in the pia mater (indicated by arrowheads in Fig. 4).

Transverse sections of the head region at E17 indicated localized expression of SC1 mRNA in neural regions, such as the developing cochlea (CO) of the ear (Fig. 5B), olfactory lobes (OL) (Fig. 5E), and also the spinal cord (SP) (Fig. 5B and E). In contrast, expression of SPARC mRNA was intense, throughout the craniofacial cartilage (C) and developing vertebrae (V) which encase the spinal cord (Figs. 5C and F), and the upper molars (UM) of the teeth (Fig. 5F). Expression of both transcripts was maintained in the pia mater (PM) (Figs. 5B and C). The marked difference in expression patterns of SC1 and SPARC was particularly notable in sagittal sections of E17 embryos 

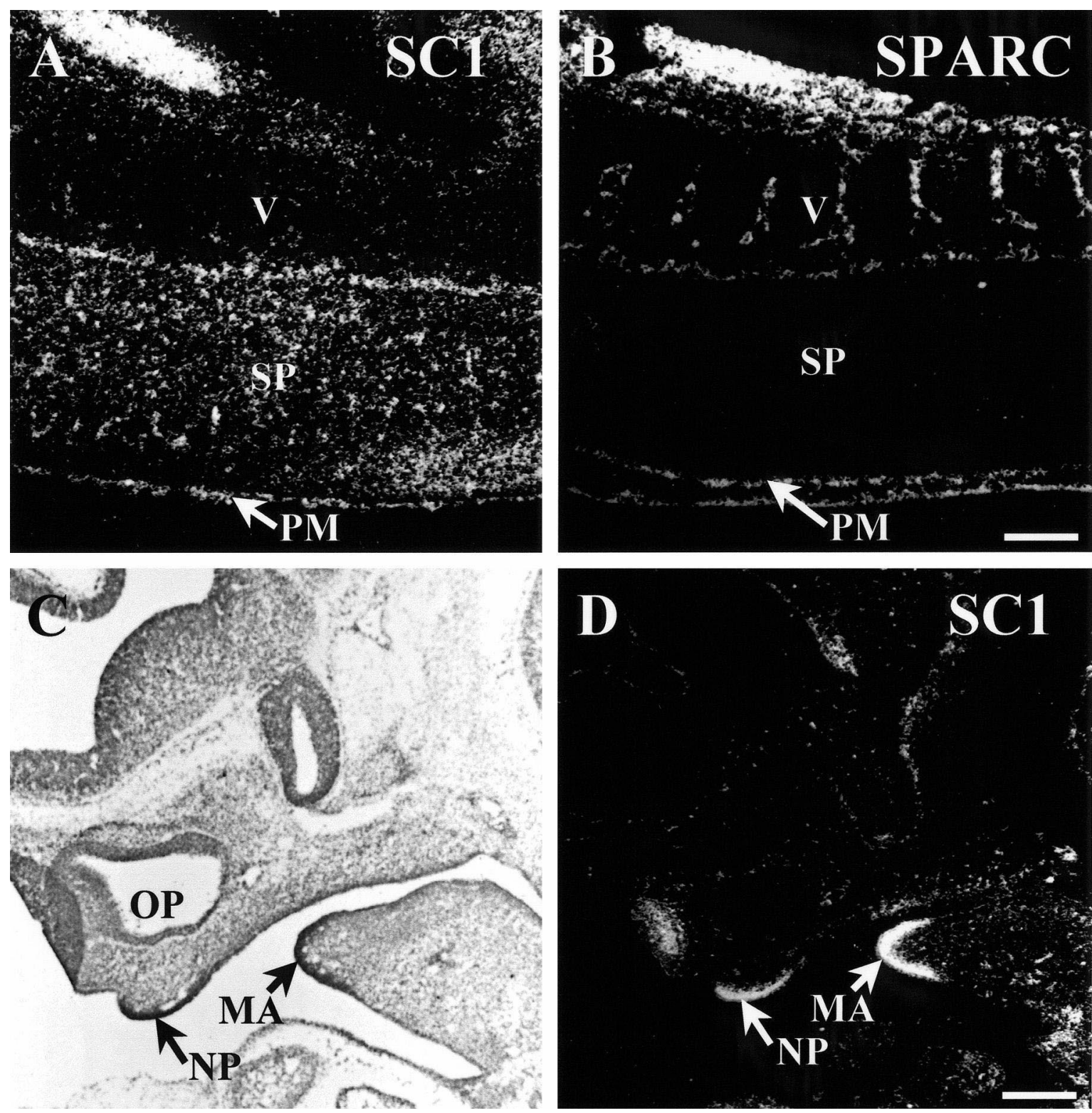

Fig. 3. Higher magnification of contrasting patterns of SC1 and SPARC mRNA expression in the E13 rat. Darkfield photos in panel A show strong SC1 mRNA expression in the spinal cord (SP), whereas SPARC mRNA (panel B) is enriched in the developing vertebrae (V) that ensheathes the spinal cord (SP). Both SC1 and SPARC mRNA are also expressed in the pia mater (PM) lining the spinal cord. Panel D shows high levels of SC1 mRNA localized to the epithelium overlying the mandibular arch (MA), and the nasal process (NP). The high density of silver grains in these regions is seen as corresponding dark areas under brightfield illumination in panel C. Scale bar $=155 \mu \mathrm{m}$ in panels A and B; bar $=125 \mu \mathrm{m}$ in panels C and D. MA, mandibular arch; NP, nasal process; OP, olfactory placode; PM, pia mater; SP, spinal cord; V, vertebrae.

(Fig. 6). Strong SC1 hybridization signal was apparent in regions of the central nervous system, such as the spinal cord (SP), brainstem (BS) and olfactory bulb (OB), as seen in Fig. 6B. In contrast, high levels of SPARC expression were associated with the skeletal system, such as ribs $(\mathrm{R})$, craniofacial cartilage $(\mathrm{C})$, vertebrae $(\mathrm{V})$ surrounding the spinal cord, nasal cartilage (NC), and Meckel's cartilage (MC) in the jaw (Fig. 6D). In Meckel's cartilage, SPARC mRNA was localized to the central region consisting of mature chondrocytes $(\mathrm{CH})$, and lower levels were apparent in the peripheral layer of undifferen- tiated cells, the perichondrium (PC) (Fig. 7F). Weak SPARC expression was also apparent in non-mineralized tissues such as lung (LU), and tongue (TO) (Fig. 6D).

Cross-sections of the spinal cord at the cervical level at E17 are shown in Fig. 7. SC1 mRNA was localized to the ventral horn $(\mathrm{VH})$ of the developing gray matter $(\mathrm{GM})$, with a strong signal apparent in the area of the central canal (CC) (Fig. 7C). The intense signal around the central canal was localized to the neuroepithelium (NE) that lines the central canal in the embryonic spinal cord (Fig. 7D). The distribution of SC1 mRNA in the ventral horn 

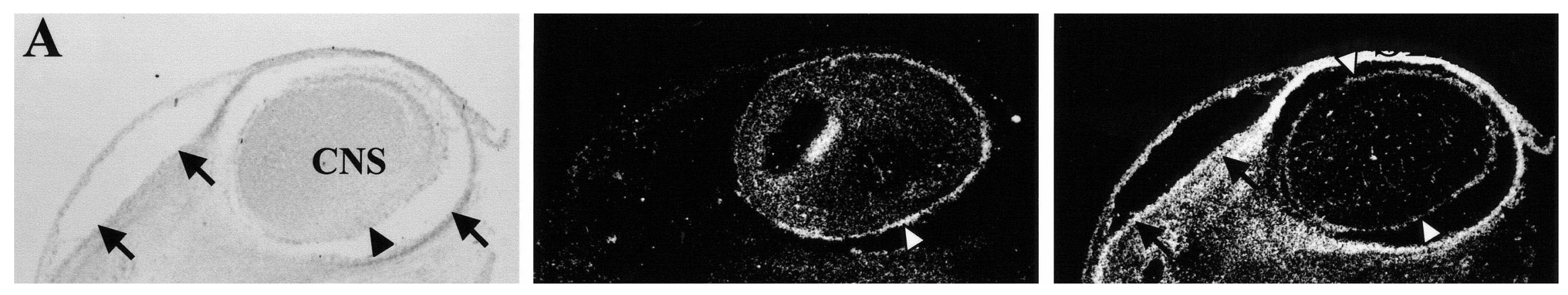

Fig. 4. SC1 and SPARC expression in the E15 cranium. Panel A is a sagittal section cut in a superficial plane of the cranial region of the E15 rat embryo stained with cresyl violet. The arrows indicate regions of cartilage. SC1 mRNA is expressed at high levels in the developing central nervous system (CNS) (panel B). In contrast, SPARC mRNA is highly enriched in cartilagenous regions, as indicated by the arrows in panel C. Localization of SC1 mRNA is not evident in the cartilagenous zones, as indicated by the arrows in panel B. Both SC1 and SPARC mRNA are also apparent in the pia mater (PM) lining the brain (indicated by arrowheads). Scale bar $=500 \mu \mathrm{m}$. CNS, central nervous system; arrowhead, pia mater; arrow, cartilagenous zone. 


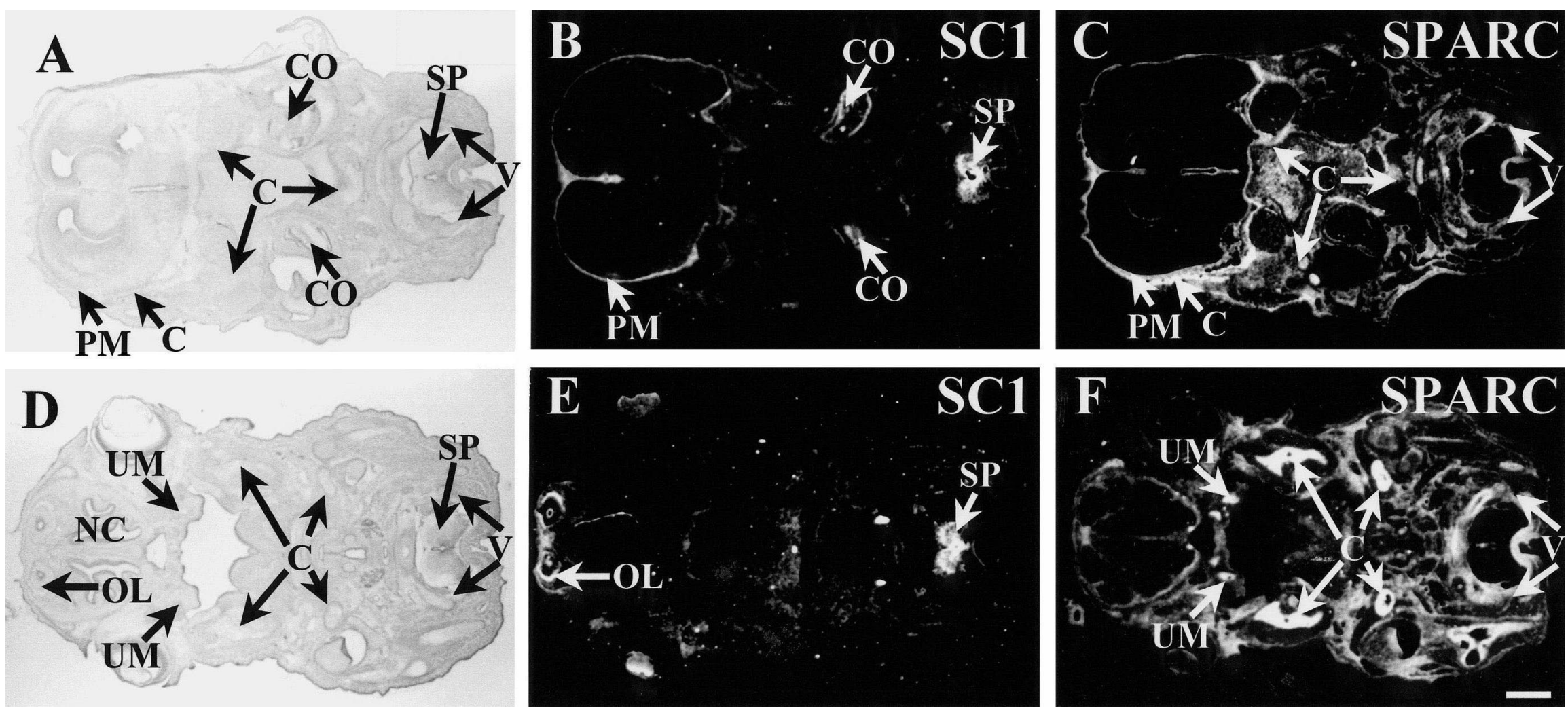

Fig. 5. SC1 mRNA is localized to neural regions whereas SPARC mRNA is expressed in cartilagenous zones. Panels A-C are transverse sections of the head region at E17. Panels D-F show transverse sections in a more medial orientation. As shown in panel B, SC1 mRNA is localized to neural regions such as the pia mater (PM), the cochlea (CO), and spinal cord (SP). SC1 mRNA is also expressed in the olfactory lobe (OL) (panel E). In contrast, SPARC mRNA is expressed throughout craniofacial cartilage (C), vertebrae (V), and developing bone as seen in panels E and F. In addition, SPARC mRNA is also apparent in the developing upper molars (UM) of the teeth (panel F). Scale bar=105 $\mu \mathrm{m}$ for all panels. C, craniofacial cartilage; CO, cochlea; NC, nasal cartilage; OL, olfactory lobe; PM, pia mater; SP, spinal cord; UM, upper molars; V, vertebrae. 

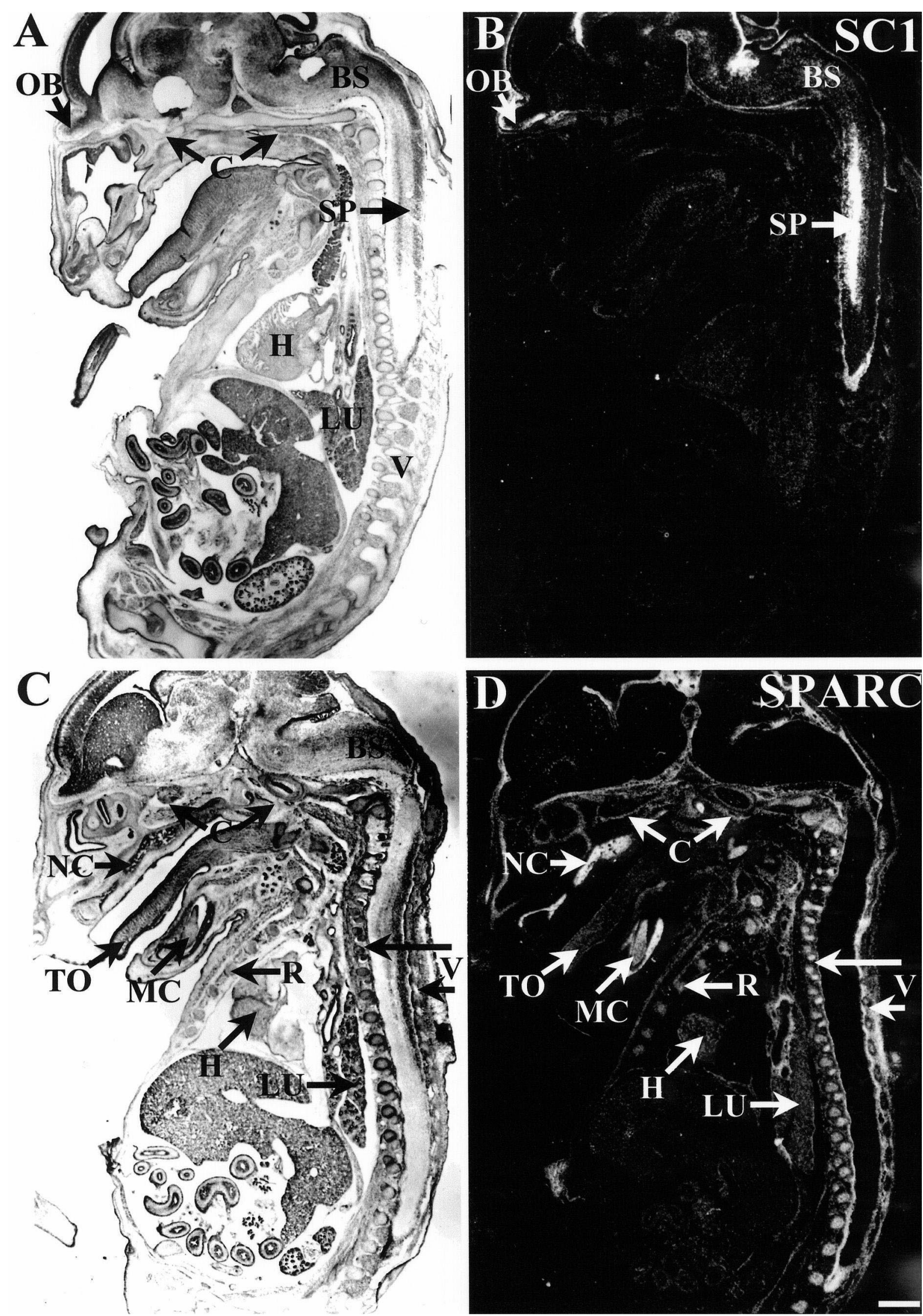

$(0 \%)$ 

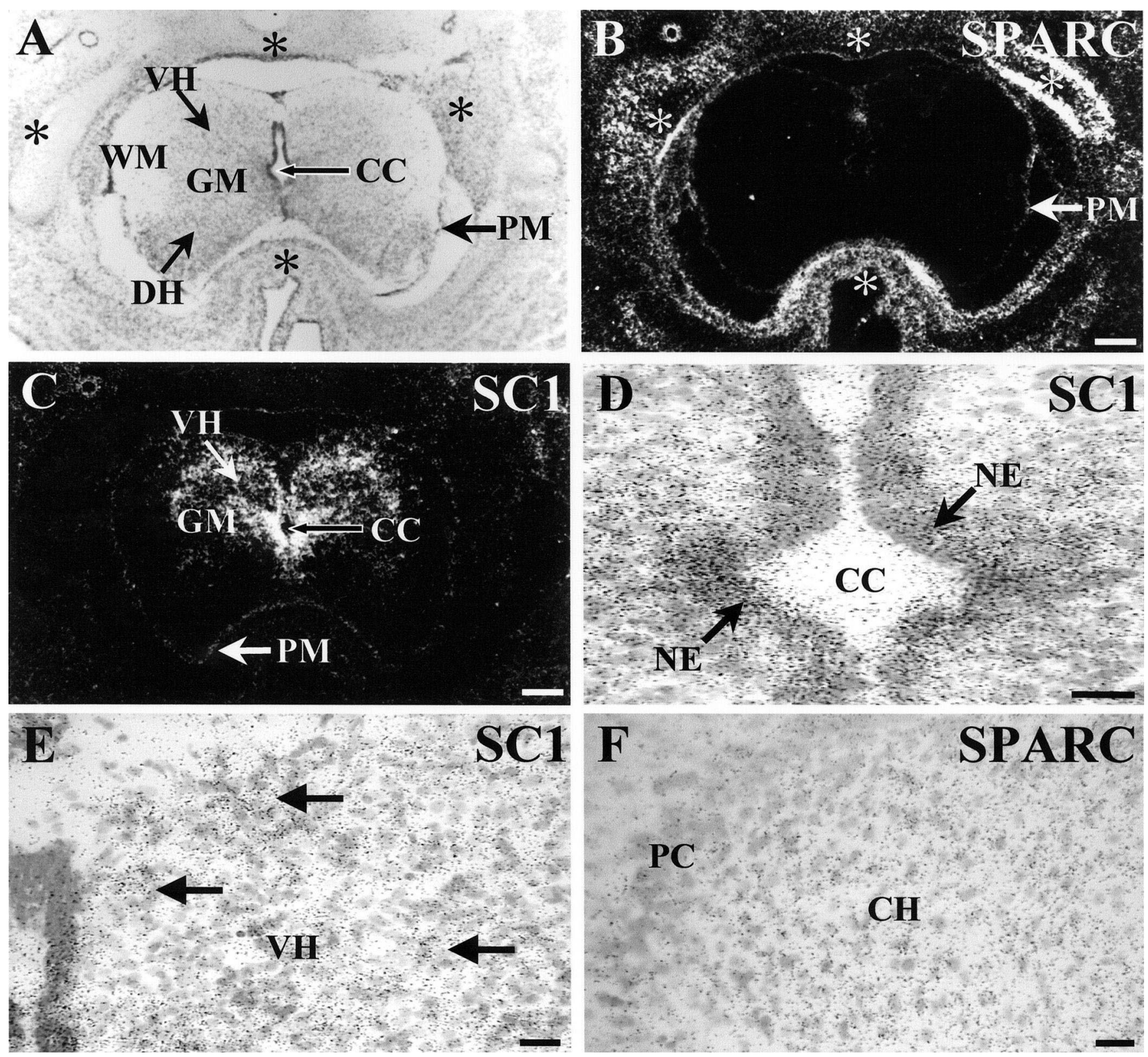

Fig. 7. Localization of SC1 and SPARC mRNA in the embryonic rat spinal cord and Meckel's cartilage. Panel A: Cresyl violet stained cross-section of E17 cervical spinal cord. Panel B: Weak SPARC expression is observed in the pia mater (PM) lining the spinal cord, but high levels of SPARC mRNA are apparent in the cartilagenous regions of the vertebrae surrounding the spinal cord, as indicated by the asterisks. Panel C: SC1 mRNA is expressed in the ventral horn $(\mathrm{VH})$ of the developing gray matter $(\mathrm{GM})$, the central canal $(\mathrm{CC})$, and the pia mater (PM). Panel D: SC1 mRNA is localized to the neuroepithelium (NE) lining the central canal (CC). Panel E: At high magnification, SC1 mRNA is observed as clusters of signal over neurons in the ventral horn, as indicated by the arrows. Panel F: In Meckel's cartilage, high levels of SPARC mRNA are apparent over chondrocytes $(\mathrm{CH})$, while lower levels are seen in the perichondrium (PC). Scale bar $=100 \mu \mathrm{m}$ for panels A-C; bar in panels D-F=26.4 $\mu \mathrm{m}$. CC, central canal; $\mathrm{CH}$, chondrocytes; DH, dorsal horn; GM, gray matter; NE, neuroepithelium; PC, perichondrium; PM, pia mater; VH, ventral horn; WM, white matter; asterisks, cartilagenous vertebral body.

Fig. 6. Regional distribution of SC1 and SPARC mRNA in sagittal sections of the E17 rat embryo. Panels A and C are counterstained with cresyl violet to show the morphology of sagittal sections of E17 whole embryos. Panels B and D are corresponding darkfield images that show SC1 and SPARC mRNA signal, respectively. As seen in panel B, SC1 mRNA is enriched in central nervous system regions such as the spinal cord (SP), brainstem (BS), and olfactory bulb $(\mathrm{OB})$. By comparison, SPARC mRNA shows a very different distribution pattern as seen in panel D. Strong expression of SPARC mRNA is associated with the skeletal system, such as the developing ribs (R), craniofacial cartilage (C), Meckel's cartilage (MC), nasal cartilage (NC), and vertebrae (V) surrounding the spinal cord. SPARC mRNA is also expressed in the heart (H), lung (LU), and tongue (TO). Scale bar=1.3 mm. BS, brainstem; C, craniofacial cartilage; H, heart; LU, lung; MC, Meckel's cartilage; NC, nasal cartilage; OB, olfactory bulb; R, ribs; SP, spinal cord; TO, tongue; V, vertebrae. 
appeared as punctate clusters of silver grains (indicated by the arrows in Fig. 7E), corresponding to the location of motor neurons. In addition, SC1 mRNA was also expressed by the pia mater (PM) lining the spinal cord (Fig. 7C). In contrast, as seen in Fig. 7B, SPARC mRNA was not detected in the spinal cord, except for expression in the pia mater (PM). SPARC mRNA was strongly expressed at E17 in the vertebrae surrounding the spinal cord, as indicated by the asterisks (Fig. 7B). These patterns of SC1 and SPARC mRNA expression were also observed in the spinal cord at the thoracic, lumbar, and saccral levels (data not shown). The differential expression pattern of SC1 and SPARC mRNA is summarized in Table 1 which shows the enrichment of SC1 mRNA in the central nervous system and high levels of SPARC mRNA in skeletal structures.

\subsection{Expression of SPARC $m R N A$ in the choroid plexus of the embryonic brain}

High levels of SPARC mRNA were evident in the choroid plexus (CP) of the E17 brain (Fig. 8C), whereas SC1 mRNA was not apparent in these regions (Fig. 8B). Expression of SPARC mRNA was evident in the choroid plexus (CP) of the lateral ventricle of the forebrain (Fig. 8C) and the choroid plexus (CP) lining the fourth ventricle (FV) of the hindbrain (Fig. 8C and E, and at high magnification in Fig. 9B). The choroid plexus lines the ventricles and secretes cerebrospinal fluid. It consists of a large number of small capillary blood vessels embedded in loose connective tissue that is covered by a layer of cuboidal epithelium. As shown in Fig. 8B and D, and at high magnification in Fig. 9A, SC1 mRNA expression was not apparent in the choroid plexus.

Table 1

Distribution of SC1 and SPARC mRNA in the embryonic rat. SC1 mRNA is enriched in regions of the central nervous system, namely the spinal cord and brain regions such at the brainstem, cerebellar anlage, olfactory bulb, and pontine tegmentum at embryonic day 17. In contrast, SPARC mRNA is enriched in vertebrae, ribs, and craniofacial cartilage including Meckel's cartilage in the jaw. SPARC mRNA is also expressed at high levels in the choroid plexus and in the cerebellar anlage ${ }^{\mathrm{a}}$

\begin{tabular}{llc}
\hline & SCI & SPARC \\
\hline Brain & +++ & + \\
Spinal cord & +++ & - \\
Pia mater & ++ & ++ \\
Choroid mater & - & +++ \\
Vertebrae & - & +++ \\
Ribs & - & +++ \\
Craniofacial & - & +++ \\
cartilage & & \\
\hline
\end{tabular}

${ }^{a}$ The relative intensity of mRNA signal is indicated by the + symbol. + (weak) to +++ (very intense signal); $-=$ no detectable mRNA signal.
3.5. SC1 and SPARC MRNA are expressed in regions of the embryonic brain associated with cell proliferation and migration

Certain regions of the embryonic brain express both $\mathrm{SC} 1$ and SPARC mRNA. For example, both transcripts were localized to proliferating neuroepithelial regions surrounding the fourth ventricle (FV) of the hindbrain. This was seen by the presence of silver grains for both probes surrounding the fourth ventricle $(\mathrm{FV})$ of the hindbrain (Figs. 8B and C). At E17, SC1 mRNA was localized to the proliferating neuroepithelial layer (NE) of the developing cerebellum (CA) (Fig. 8D and at higher magnification in Fig. 9A), the neuroepithelium lining the isthmal canal (IC) (Fig. 8D), the neuroepithelium comprising the tegmentum (T) lining the mesencephalic vesicle (MV) and the tegmentum of the developing pons (PT) (Fig. 8D). A similar pattern of expression in these neuroepithelial regions of the hindbrain was also apparent with the SPARC probe, although at lower levels (Fig. 8E). Therefore, both transcripts appear to be expressed in regions of the embryonic hindbrain that contain mitotic cells.

SC1 and SPARC were also expressed in areas of the hindbrain actively undergoing cell migration, such as the cerebellum. Morphogenetic changes take place in the cerebellum at E17. For example, the external germinal layer (EGL) is progressively dispersed over the surface of the developing cerebellar cortex. The EGL is a band of cells that is formed at the posterior pole of the cerebellar neuroepithelium [2]. The EGL spreads forward and then downward over the entire surface of the cerebellum. The path of migration of the granule cells of the EGL is shown by the bracketed arrows in Fig. 8D and $\mathrm{E}$ at low magnification, and by the arrow in Fig. $8 \mathrm{~F}$ at higher magnification. Interestingly, both $\mathrm{SC} 1$ and SPARC mRNA were expressed in the path of migrating granule cells, as indicated by the arrow in Fig. 8F, and in the fibrous zone (FZ) next to the EGL.

The mRNA expression pattern of these related ECMs was then examined in the E17 rat cerebral cortex which is also undergoing proliferative and migratory events. In the developing cortex, waves of cortical neurons leave the proliferative ventricular zone (VZ) and migrate through the intermediate zone (IZ) and subplate (SPL) to enter the cortical plate (CPL) and take up positions just below the marginal zone (MZ) [4]. The cellular layers of the E17 rat cortex are shown in Fig. 9C at low magnification. As seen in Figs. 9D and E, SC1 and SPARC mRNA were localized to the marginal zone (MZ) of the E17 cortex. However, $\mathrm{SC} 1$ and SPARC mRNA expression was not apparent in the cortical plate (CPL) through which neuroblasts migrate (Figs. 9D and E), nor was expression apparent in the proliferative ventricular zone (data not shown). Since SC1 and SPARC mRNA were not detectable in these regions of cell proliferation and migration as was observed in the 

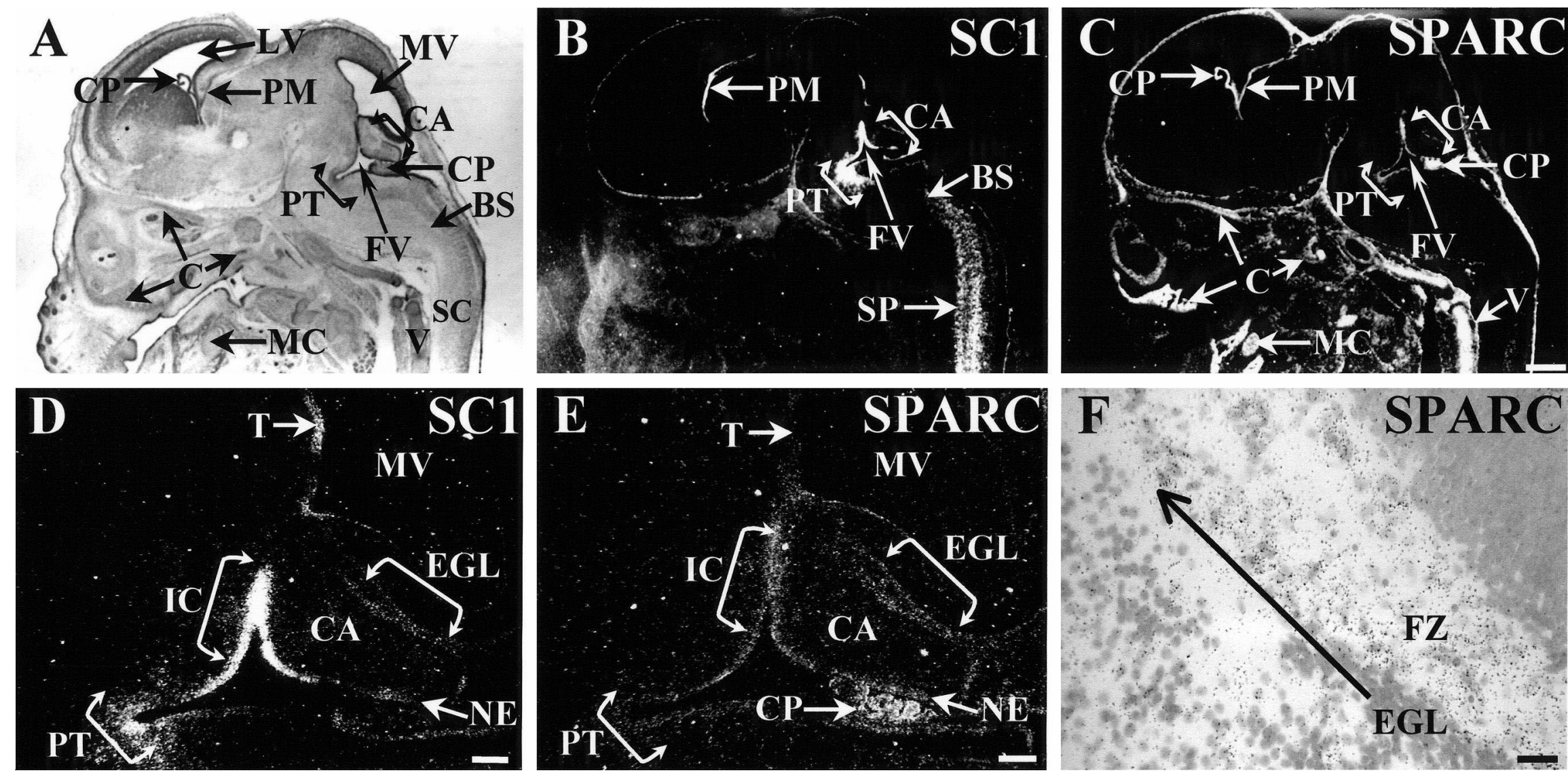

Fig. 8. Expression of SC1 and SPARC mRNA in the E17 hindbrain. Panels A-C are sagittal sections of E17 heads that show the overall distribution of SC1 and SPARC mRNA in the central nervous system. The lower panels (D-F) are high magnification views of the developing cerebellum and region of the fourth ventricle of the E17 hindbrain. Panel A: Tissue morphology as indicated by brightfield microscopy. Panel B: SC1 mRNA is seen in the spinal cord (SP), and in CNS regions such as the pontine tegmentum (PT), brainstem (BS), cerebellar anlage (CA), and pia mater (PM). Panel C: SPARC mRNA continues to be strongly expressed in the cartilage of the cranium (C), Meckel's cartilage (MC), and as indicated with arrows, the pia mater (PM) and choroid plexus (CP). Panels D and E indicate mRNA distribution in the hindbrain under darkfield microscopy. Panel D: SC1 mRNA is expressed in the neuroepithelium (NE) of the developing cerebellum (CA), the neuroepithelium lining the isthmal canal (IC), the tegmentum (T) of the mesencephalic vesicle (MV), and the tegmentum of the pons (PT). The square brackets labelled EGL indicate the migration of granule cells of the cerebellum. Panel E: A similar pattern of expression for SPARC mRNA is evident in the developing cerebellum (CA), as is seen for SC1 in panel D, however lower levels of SPARC mRNA are associated with the neuroepithelial regions (NE, IC, T, PT) and SPARC is strongly expressed in the choroid plexus (CP). Panel F: High magnification view of the developing cerebellum under brightfield illumination shows the distribution of SPARC mRNA in the path of migrating granule cells of the external germinal layer (EGL) as indicated by the arrow, and in the fibrous zone (FZ) next to the EGL. Scale bar=1.1 mm in panels A, B, and C; bar $=220 \mu \mathrm{m}$ in panels D and E; bar=26.4 $\mu \mathrm{m}$ in panel F. BS, brainstem; C, craniofacial cartilage; CA, cerebellar anlage; CP, choroid plexus; EGL, external germinal layer; FV, fourth ventricle; FZ, fibrous zone; IC, isthmal canal; LV, lateral ventricle; MC, Meckel's cartilage; MV, mesencephalic vesicle; NE, neuroepithelium; PM, pia mater; PT, pontine tegmentum; SP, spinal cord; T, tegmentum; V, vertebrae; arrow, path of migrating granule cells. 

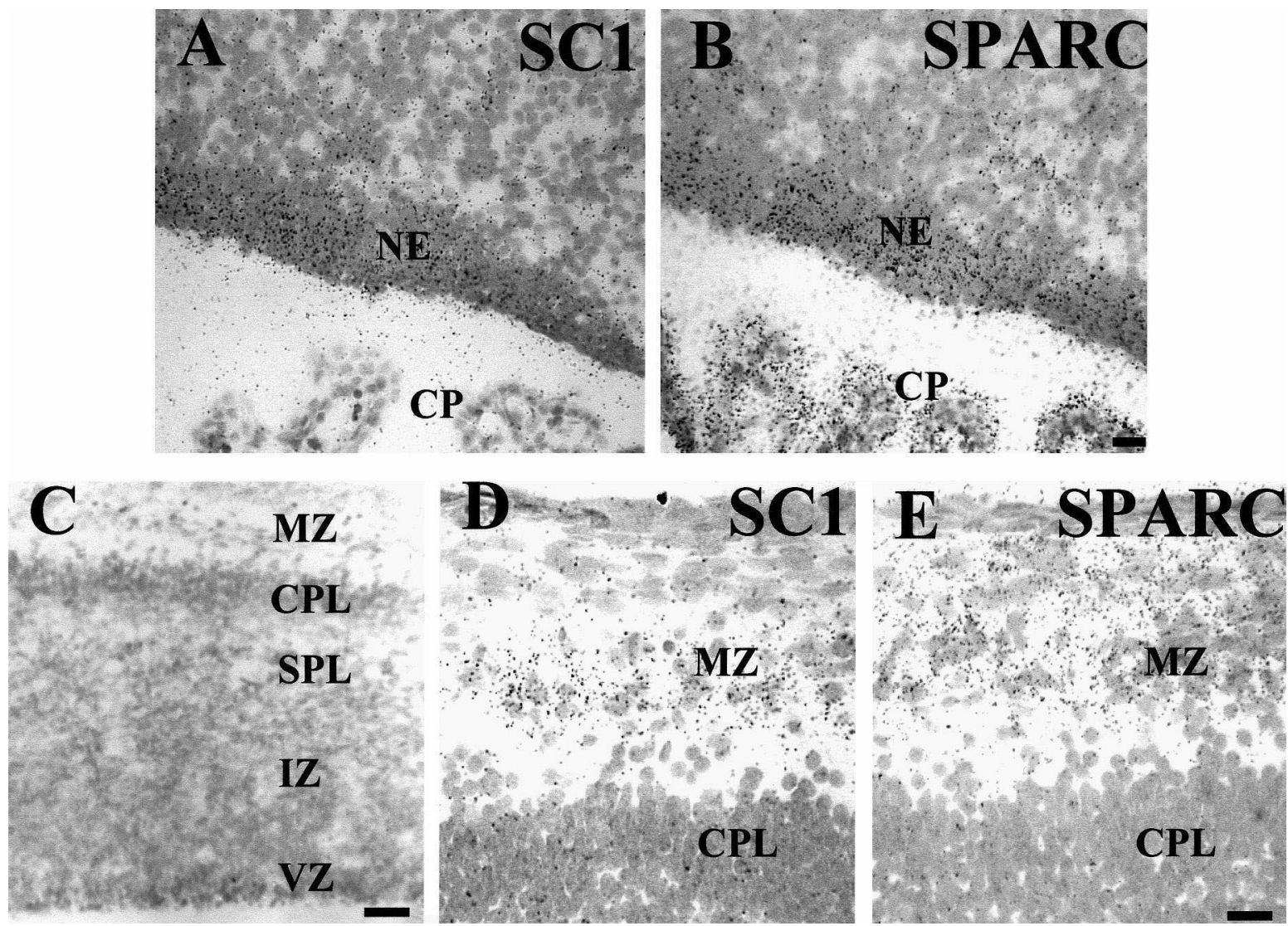

Fig. 9. Distribution of SC1 and SPARC mRNA in the E17 cerebral cortex and choroid plexus. Panel A: SC1 mRNA is associated with the neuroepithelium of the cerebellar anlage (NE), but no signal is apparent in the choroid plexus (CP) of the fourth ventricle. Panel B: SPARC mRNA is expressed in both the neuroepithelium (NE) of the developing cerebellum and the choroid plexus (CP) of the fourth ventricle. Panel C: Low magnification view of a cresyl violet stained section indicating the cellular layers of the developing cortex. Panel D: Signal corresponding to SC1 mRNA is localized to the marginal zone (MZ) of the developing cortex, while the cortical plate (CPL) remains unlabelled. Panel E: SPARC mRNA is distributed more diffusely in the marginal zone (MZ). Scale bar $=26.4 \mu \mathrm{m}$ for panels A and B; bar $=55 \mu \mathrm{m}$ for panel C; bar $=26.4 \mu \mathrm{m}$ for panels D and E. CPL, cortical plate; CP, choroid plexus; IZ, intermediate zone; MZ, marginal zone; NE, neuroepithelium; SPL, subplate; VZ, ventricular zone.

cerebellum, it appears that these ECMs may not contribute in regulating proliferative and migratory events in the developing cerebral cortex.

\section{Discussion}

In the central nervous system, ECM molecules help regulate many aspects of neural development including cell differentiation, cell migration, and process outgrowth by modulating adhesive and anti-adhesive interactions [39]. SC1 and SPARC are related ECM glycoproteins which exhibit anti-adhesive properties [11,29]. During postnatal development of the brain, SC1 shows a glial to neuronalenriched pattern of expression in the forebrain whereas SPARC is expressed by glial cell populations postnatally and in the adult brain. In the adult cerebellum, both SC1 and SPARC are expressed in Bergmann glial cells and their fibers [20,21], and transport of SC1 mRNA in Bergmann glial processes is developmentally regulated [24]. In the present study, we were interested in determining whether
SC1 and SPARC mRNA show distinct or overlapping patterns of expression in the embryonic rat.

SC1 mRNA is expressed in the central nervous system of the E13 and E15 embryo, and is enriched in the hindbrain and spinal cord of the E17 rat. Cross-sections of the spinal cord in the E17 embryo show a punctate distribution of SC1 mRNA in the ventral gray matter which correlates with ventral horn motor neurons. Furthermore, SC1 mRNA is not detected in white matter areas of the spinal cord which do not contain neurons. Other studies support our finding that $\mathrm{SC} 1$ is enriched in the embryonic nervous system $[19,34]$. However, in contrast to the results of Soderling et al. [34], we did not detect SC1 mRNA in cartilagenous regions or in developing bone.

In contrast to SC1, SPARC mRNA is predominantly expressed in cartilagenous regions of the E13 and E15 rat and in craniofacial cartilage, ribs, and developing bone in the E17 embryo. The cartilage to bone transition occurs at E17 in the rat. As reflected in the expression pattern, SPARC mRNA is widely distributed in both membranous and endochondral ossification models of bone develop- 
ment, such as craniofacial cartilage of the skull, and ribs and vertebrae of the axial skeleton, respectively. In addition, high levels of SPARC mRNA are associated with mature chondrocytes of Meckel's cartilage. SPARC is one of the most abundant noncollagenous proteins in bone. Interestingly, the mRNA encoding the calcium-binding protein $\beta$-S100 is predominantly expressed in craniofacial cartilage of the E14 rat [18]. Like SPARC, $\beta-S 100$ mRNA is enriched in the proliferative neuroepithelium of the mesencephalic vesicle and fourth ventricle of the rat embryo, and $\beta$-S100 is also expressed in Bergmann glial cells of the cerebellum [17], as is SPARC and SC1. Previous studies have suggested that SPARC expression in mouse and human embryos is associated with regions of active tissue remodeling, such as the developing organs, gut, blood vessels, and bone [12,25,30]. In the embryonic CNS, SPARC mRNA appears to correlate with developing blood vessels. For example, our present studies demonstrate an intense SPARC mRNA signal in the vascular-rich choroid plexus of the lateral and fourth ventricles of the E17 rat.

Interestingly, at E13, SC1 mRNA is transiently localized to the epithelium of the mandibular component of the first branchial arch. Specific localization of SC1 mRNA to the mandibular component of the first branchial arch was also noted by whole mount in situ studies in the E9.5-10 mouse embryo [28]. Tenascin shows a similar localized expression in the mandibular epithelium of the chick [7]. The first branchial arch gives rise to the complex facial structure of the mandibular and maxillary processes. The normal growth and development of the first branchial arch into a differentiated mandible involves cell migration of cranial neural crest cells and paraxial mesoderm, cell interactions with ECM components, and epithelial-mesenchymal interactions [40]. The initial regulation for cell differentiation to a chondrogenic, osteogenic, or odontogenic lineage appears to be controlled by inductive signals from the E10-11 mouse oral mandibular epithelia and the interaction with the underlying mesenchyme [40]. For example, BMP-4 and growth factors such as EGF and Fgf-8, have been shown to be key signaling molecules from the oral epithelium capable of inducing mesenchymal genes in the mandibular arch $[16,37,38]$. The localized expression of SC1 mRNA in the oral mandibular epithelium of the E13 rat may play a role in regulating inductive signals from the epithelium to the underlying mesenchyme via interactions with growth factors, and in the tissue remodeling of the developing mandible.

In the embryonic brain, SC1 and SPARC mRNA are both expressed in certain regions. For example, both transcripts are localized to neuroepithelial regions of the E17 hindbrain. The most intense hybridization signal for $\mathrm{SC} 1$ in the spinal cord is localized to the neuroepithelium surrounding the central canal. The neuroepithelium contains progenitor cells that are multipotential, giving rise to both glia and neurons. This multipotentiality is pro- gressively restricted by a series of cell fate decisions regulated by environmental factors through cell-cell and cell-matrix interactions. Thus, cell fate choice may be influenced by the expression of temporally regulated cues within the neuroepithelial region. SC1 and SPARC may play a role in this process, regulating proliferation and/or differentiation. Similarly, the mRNA encoding BEHAB (secreted, brain-enriched hyaluronan-binding protein), was shown to be expressed in zones of mitotic activity and it was suggested that BEHAB may play a role in glial cell proliferation and differentiation [14]. In vitro studies in cultured bovine aortic endothelial cells suggest SPARC decreases cell proliferation [8,31]. However, our present in vivo studies in the embryonic nervous system indicate that SPARC and SC1 are expressed in proliferating regions of the hindbrain.

In the embryonic cerebellum, SC1 and SPARC mRNA are both expressed in regions exhibiting cell migration. At E17 in the rat, the granule cells of the external germinal layer (EGL) progressively spread over the entire surface of the cerebellum. Interestingly, both $\mathrm{SC} 1$ and SPARC mRNA are localized to the path of these migrating granule cells and in the fibrous zone next to the EGL. Granule cell migration over the surface of the cerebellum continues until just before birth, which correlates with the downregulation of SC1 and SPARC transcripts in the postnatal day 1 EGL as shown previously [20,21]. The localization of SC1 and SPARC mRNA in the fibrous zone and particularly in the path of the migrating EGL suggests that these anti-adhesive ECMs may play a role in promoting the migratory path of these cells.

$\mathrm{SC} 1$ and SPARC expression patterns in the embryonic cerebral cortex were also examined since the E17 cortex consists of discrete proliferative zones and regions undergoing cell migration. Cortical neurons are thought to migrate from the ventricular zone to their final positions in the cortical plate along radial glial guides. Radial glia send processes to the pial surface, and it is thought that the ECM plays a role in this migration [27]. For example, in the developing rat cortex, fibronectin and chondroitin sulfate proteoglycan are found throughout the proliferative zone, marginal zone and subplate, and fibronectin appears to be associated with radial glia [33]. Expression of these ECM molecules is rapidly downregulated as the cortical plate begins to differentiate into cortex. Laminin is also transiently expressed in the subplate layer through which neuroblasts migrate [13]. In comparison, SC1 and SPARC mRNA are localized to the marginal zone and the expression of either transcript is not detected in the ventricular zone consisting of proliferating progenitor cells, nor in the regions of cell migration. Clearly, the developing cortex is an ECM-rich region and perhaps the anti-proliferative and anti-adhesive functions of SC1 and SPARC are not essential for cortical development. In support of this, previous studies [21,22] show that SC1 and SPARC exhibit restricted expression in the postnatal and adult cerebral 
cortex, whereas both of these ECMs show very strong expression in the cerebellum.

Recent reports on the characterization of mice deficient for SPARC and the generation of SC1 nulls indicate that these knockouts appear to undergo normal embryonic development. Surprisingly, SPARC nulls are viable, fertile, and appear to develop normally except for the formation of early-onset cataracts $[3,9,26]$ and development of osteopenia in some mice [6]. Similarly, SC1 knockouts have been reported to show no obvious deficits [19]. These knockout models suggest functional redundancy in these ECM glycoproteins. It will be interesting to see what phenotype is generated in mice carrying a null mutation in both the SC1 and SPARC genes.

The distinctive spatiotemporal expression patterns of SC1 and SPARC mRNA in the rat embryo reflect the matricellular and multifunctional properties of these ECM glycoproteins. The primary structure of SPARC has been highly conserved in the evolution of organisms, ranging from $C$. elegans to mammals [32,35]. Thus, the presence of SPARC predates the emergence of bony tissue. It is clear that SPARC has important roles other than in tissue mineralization given its distribution in certain regions of the CNS and in other non-mineralized tissues. In contrast to SPARC, the SC1 gene appears to be more recent. To date, SC1 has been cloned from human (hevin) [10], rat [15], and mouse [34], but does not appear to be present in the $C$. elegans or Drosophila genome. It seems that SC1 arose later in evolution, perhaps in response to more elaborate developments of the nervous system.

\section{Acknowledgements}

This study was supported by NSERC Canada to IRB. The authors would like to thank Sheila Rush for critical reading of the manuscript.

\section{References}

[1] J.C. Adams, F.M. Watt, Regulation of development and differentiation by the extracellular matrix, Development 117 (1993) 1183-1198.

[2] J. Altman, Development of the Cerebellum: in Relation to its Evolution, Structure, and Functions, CRC Press, Boca Raton, 1997.

[3] J.A. Bassuk, T. Birkebak, J.D. Rothmier, J.M. Clark, A. Bradshaw, P.J. Muchowski, C.C. Howe, J.I. Clark, E.H. Sage, Disruption of the SPARC locus in mice alters the differentiation of lenticular epithelial cells and leads to cataract formation, Exp. Eye Res. 68 (1999) 321-331.

[4] S.A. Bayer, J. Altman, Neocortical Development, Raven Press, New York, 1991.

[5] P. Bornstein, Diversity of function is inherent in matricellular proteins: an appraisal of thrombospondin 1, J. Cell Biol. 130 (1995) 503-506.

[6] A. Delaney, M. Amling, M. Priemel, G. Delling, C. Howe, R. Baron, E. Canalis, Osteonectin-null mice develop severe osteopenia, Bone 23 (1998) 199S.
[7] L.L. Dunlop, B.K. Hall, Relationships between cellular condensation, preosteoblast formation and epithelial-mesenchymal interactions in initiation of osteogenesis, Int. J. Dev. Biol. 39 (1995) 357-371.

[8] S.E. Funk, E.H. Sage, The $\mathrm{Ca}^{2+}$-binding glycoprotein SPARC modulates cell cycle progression in bovine aortic endothelial cells, PNAS 88 (1991) 2648-2652.

[9] D.T. Gilmour, G.J. Lyon, M.B. Carlton, J.R. Sanes, J.M. Cunningham, J.R. Anderson, B.L. Hogan, M.J. Evans, W.H. Colledge, Mice deficient for the secreted glycoprotein SPARC/osteonectin/BM40 develop normally but show severe age-onset cataract formation and disruption of the lens, EMBO J. 17 (1998) 1860-1870.

[10] J.P. Girard, T.A. Springer, Cloning from purified high endothelial venule cells of hevin, a close relative of the antiadhesive extracellular matrix protein SPARC, Immunity 2 (1995) 113-123.

[11] J.P. Girard, T.A. Springer, Modulation of endothelial cells adhesion by hevin, an acidic protein associated with high endothelial venules, J. Biol. Chem. 271 (1996) 4511-4517.

[12] P.W.H. Holland, S.J. Harper, J.H. McVey, B.L.M. Hogan, In vivo expression of mRNA for the protein $\mathrm{Ca}^{2+}$-binding (osteonectin) revealed by in situ hybridization, J. Cell Biol. 105 (1987) 473-482.

[13] D.D. Hunter, R. Llinas, M. Ard, J.P. Merlie, J.R. Sanes, Expression of S-laminin and laminin in the developing rat central nervous system, J. Comp. Neurol. 323 (1992) 238-251.

[14] D.M. Jaworski, G.M. Kelly, S. Hockfield, The CNS-specific Hyaluronan-binding protein BEHAB is expressed in ventricular zones coincident with gliogenesis, J. Neurosci. 15 (1995) 1352-1362.

[15] I.G. Johnston, T. Paladino, J.W. Gurd, I.R. Brown, Molecular cloning of SC1: a putative brain extracellular matrix glycoprotein showing partial similarity to osteonectin/BM40/SPARC, Neuron 2 (1990) 165-176.

[16] J.E. Kronmiller, W.B. Upholt, E.J. Kollar, Expression of epidermal growth factor mRNA in the developing mouse mandibular process, Arch. Oral. Biol. 36 (1991) 405-410.

[17] C.F. Landry, G.O. Ivy, R.J. Dunn, A. Marks, I.R. Brown, Expression of the gene encoding the $\beta$-S100 protein in the developing rat brain analyzed by in situ hybridization, Mol. Brain Res. 6 (1989) 251-262.

[18] C.F. Landry, J.H. Youson, I.R. Brown, Expression of the $\beta$-S100 gene in brain and craniofacial cartilage of the embryonic rat, Dev. Neurosci. 12 (1990) 225-234.

[19] P.J. McKinnon, S.K. McLaughlin, M. Kapsetaki, R.F. Margolskee, Extracellular matrix-associated protein $\mathrm{SC} 1$ is not essential for mouse development, Mol. Cell Biol. 20 (2000) 656-660.

[20] D.B. Mendis, S. Shahin, J.W. Gurd, I.R. Brown, Developmental expression in the rat cerebellum of SC1, a putative brain extracellular matrix glycoprotein related to SPARC, Brain Res. 633 (1994) 197-205.

[21] D. B Mendis, I.R. Brown, Expression of the gene encoding the extracellular matrix glycoprotein SPARC in the developing and adult mouse brain, Mol. Brain Res. 24 (1994) 11-19.

[22] D.B. Mendis, S. Shahin, J.W. Gurd, I.R. Brown, SC1, a SPARCrelated glycoprotein, exhibits features of an ECM component in the developing and adult brain, Brain Res. 713 (1996) 53-63.

[23] K. Motamed, Review: SPARC (osteonectin/BM-40), Int. J. Biochem. Cell Biol. 31 (1999) 1363-1366.

[24] A.J. Mothe, I.R. Brown, Selective transport of SC1 mRNA, encoding a putative extracellular matrix glycoprotein, during postnatal development of the rat cerebellum and retina, Mol. Brain Res. 76 (2000) 73-84.

[25] S. Mundlos, B. Schwahn, T. Reichert, B. Zabel, Distribution of osteonectin mRNA and protein during human embryonic and fetal development, J. Histochem. Cytochem. 40 (1992) 283-291.

[26] K. Norose, J.I. Clark, N.A. Syed, A. Basu, E. Heber-Katz, E.H. Sage, C. C Howe, SPARC deficiency leads to early-onset cataractogenesis, Invest. Ophthalmol. Vis. Sci. 39 (1998) 2674-2680.

[27] A.L. Pearlman, A.M. Sheppard, Extracellular matrix in early cortical development, Prog. Brain Res. 108 (1996) 119-134. 
[28] M. Ringuette, I. Roger, S. Varmuza, S. Rush, I.R. Brown, Expression of SC1 is associated with the migration of myotomes along the dermomyotome during somitogenesis in early mouse embryos, Dev. Genes Evol. 208 (1998) 403-406.

[29] E.H. Sage, R.B. Vernon, S.E. Funk, E.A. Everitt, J. Angello, SPARC, a secreted protein associated with cellular proliferation, inhibits cell spreading in vitro and exhibits $\mathrm{Ca}^{2+}$-dependent binding to the extracellular matrix, J. Cell Biol. 109 (1989) 341-356.

[30] E.H. Sage, R.B. Vernon, J. Decker, S. Funk, M.L. Iruela-Arispe, Distribution of the calcium-binding protein SPARC in tissues of embryonic and adult mice, J. Histochem. Cytochem. 37 (1989) 819-829.

[31] E.H. Sage, J. Bassuk, J.C. Yost, M.J. Folkman, T.F. Lane, Inhibition of endothelial cell proliferation by SPARC is mediated through a $\mathrm{Ca}^{2+}$-binding E/F-hand sequence, J. Cell Biochem. 57 (1995) $127-140$.

[32] J. Schwarzbauer, C.S. Spencer, The Caenorhabitis elegans homolog of the extracellular calcium binding protein SPARC/osteonectin affects nematode body morphology and mobility, Mol. Biol. Cell 4 (1993) 941-952.

[33] A.M. Sheppard, S.K. Hamilton, A.L. Pearlman, Changes in the distribution of extracellular matrix components accompany early morphogenetic event of mammalian cortical development, J. Neurosci. 11 (1991) 3928-3942.
[34] J.A. Soderling, M.J. Reed, A. Corsa, E.H. Sage, Cloning and expression of murine SC1, a gene product homologous to SPARC, J. Histochem. Cytochem. 45 (1997) 823-835.

[35] A. Swaroop, B.L.M. Hogan, U. Franke, Molecular analysis of the cDNA for human SPARC/osteonectin/BM-40: sequence, expression, and localization of the gene to chromosome 5q31-133, Genomics 2 (1998) 37-47.

[36] J. Termine, H. Kleinman, S. Whitson, K. Conn, M. McGarvey, G. Martin, Osteonectin, a bone-specific protein linking mineral to collagen, Cell 26 (1981) 99-105.

[37] A.S. Tucker, K.L. Matthews, P.T. Sharpe, Transformation of tooth type induced by inhibition of BMP signaling, Science 282 (1998) $1136-1138$

[38] A.S. Tucker, G. Yamada, M. Grigoriou, V. Pachnis, P.T. Sharpe, Fgf-8 determines rostral-caudal polarity in the first branchial arch, Development 126 (1999) 51-61.

[39] K. Venstrom, L.F. Reichardt, Review: Role of extracellular matrix molecules and their receptors in the nervous system, FASEB J. 7 (1993) 996-1003.

[40] Z. Werb, J.R. Chin, Review: Extracellular matrix remodeling during morphogenesis, Ann. NY Acad. Sci. (1998) 110-118.

[41] Q. Yan, E.H. Sage, Review: SPARC, a matricellular glycoprotein with important biological functions, J. Histochem. Cytochem. 47 (1999) 1495-1505. 